\title{
A Fade-Compensation Technique for Digital Land Mobile Satellite Systems
}

(Updated manuscript)

\author{
In submission to \\ International Journal of Satellite Communications
}

By

H. K. Lau and S. W. Cheung*

Communications Research Group

Department of Electrical and Electronic Engineering

The University of Hong Kong

Pokfulam Road

HONG KONG

* Please send all correspondence to Dr S W Cheung, email: swcheung@hkueee.hku.hk 


\title{
A Fade-Compensation Technique for Digital Land Mobile Satellite Systems
}

\author{
H. K. Lau and S. W. Cheung \\ Communications Research Group \\ Department of Electrical and Electronic Engineering \\ The University of Hong Kong \\ Pokfulam Road \\ Hong Kong
}

\section{ABSTRACT}

The paper proposes a novel fade-compensation algorithm using a pilot symbol-aided technique for digital land mobile satellite systems. In a conventional pilot symbol-aided system, a pilot symbol from a known pseudoradom-symbol sequence is inserted periodically into the data-symbol sequence in the transmitter. At the receiver, these pilot symbols are extracted from the received signal and used to estimate the signal distortion introduced in the fading channel. The resultant estimate is then used to correct the fading effects in the received data symbols. In the paper, a novel fade-compensation technique that uses both the pilot symbols and data symbols is proposed. A series of computer-simulation tests has been carried out to assess the effectiveness of the technique on the bit-error-rate (BER) performances of an uncoded 16-ary phase-shift keyed (16PSK) and an uncoded 16-ary quadrature-amplitude modulated (16QAM) signals over the land mobile satellite channels. The results have shown that, substantial improvements in the BER performances of the systems can be obtained, relative to those using only the pilot symbols. 


\section{Introduction}

In recent years, mobile satellite communications services have undergone a new development phase in both technologies and applications. In addition to the existing services such as the maritime mobile, the land mobile and the aeronautical mobile services, the concepts of satellite-based personal communications services (PCS) have been emerged [1-5]. The PCS demands for a higher channel capacity and so requires a better utilization of the RF spectrum. Therefore, signals with better spectral efficiencies than the conventional quaternary-phase keyed (QPSK) or Gaussian phase-shift keyed (GMSK) signals are needed to be considered. Among the spectrally-efficient signals, 16-ary phase-shift keyed (16PSK) and 16-ary quadrature-amplitude modulated (16QAM) signals are promising candidates because of their relative simplicity of implementation and good error-rate performances through linear channels [6-8]. Unfortunately, efficient transmission of these signals in mobile environments is difficult to achieve because the wide tracking bandwidth requirement when conventional carrier recovery schemes are used [9].

Recently, the pilot symbol-aided transmission techniques have been proposed for coherent transmission of spectrally-efficient signals over the fading channels [8, 10-13]. In a pilot symbol-aided system, the transmitted data-symbol sequence is divided into frames of data symbols. A known pilot symbol is then inserted into each of these frames for transmission. At the receiver, the pilot symbol is extracted from the received signal and used to estimate the signal distortion introduced in the fading channel. The resultant estimate is then used to correct the fading effects of the data symbols. Several algorithms have been proposed to estimate the fading effects using the received pilot symbols, including interpolation, interpolation with Kalman filtering, and using one, two or three pilot symbols with applications to trellis-coded modulation (TCM) [8, 10-13]. However, in these studies, little emphasis has been put on the time delay of the fading compensation process (distortion estimation and correction). The time delay introduced could be critical for voice transmission over the satellite channels, therefore, compensation techniques with mininal complexity and 
storage delay are desirable. A simple algorithm uses an extrapolation technique has been proposed by the authors to minimize the time-delay in the estimation process [13].

In the paper, the work in [13] is extended. A novel fade-compensation technique uses both the pilot symbols and data symbols to enhance the accuracy of the distortion estimation process is proposed. The technique introduces virtually zero storage delay to the received message because the compensation process can start immediately after the first symbol (the pilot symbol) of the frame is received; thus it is suitable for land mobile satellite systems. A series of computer-simulation tests has been carried out to assess the effectiveness of the proposed technique on the bit-error-rate (BER) performances of the uncoded 16PSK and uncoded 16QAM signals over the land mobile satellite channels. It is assumed that the systems are operating at a rate $32 \mathrm{~kb} / \mathrm{s}$ or 8 kbauds with the signal carrier frequency of 1.8 GHz. Tests have been carried out using various frame lengths of the transmitted signals and with the mobile travelling at a radial velocities of $24 \mathrm{~km} / \mathrm{hr}, 48 \mathrm{~km} / \mathrm{hr}$, or $96 \mathrm{~km} / \mathrm{hr}$, thus resulting in the worst normalized Doppler spreads of $0.005,0.01$ or 0.02 of the symbol rate, respectively. The results have shown that, by using the proposed technique in estimating the fading effects, the BER performances of both the uncoded 16PSK and the uncoded 16QAM signals can be improved substantially, relative to those using only the pilot symbols. 


\section{System Model}

The baseband equivalent data-transmission model used in the study is shown in Fig. 1. The information to be transmitted is carried by the binary digits $\left\{u_{n}\right\}$. When the encoder has received the binary information $\left\{u_{n}\right\}$ at time $t=n T$ seconds (where $n$ is a positive integer and $T$ is the symbol duration), it maps these signals into the appropriate data symbol $d_{n}$ according to the 16PSK or 16QAM signal constellations as shown in Fig. 2. For every ( $L-1)$-data symbols, a pilot symbol from a known pseudorandom-symbol sequence $\left\{p_{n}\right\}$ is inserted to form a frame of $L$-symbol long as shown in Fig. 3. (A pseudorandom sequence of pilot symbols is used to avoid transmitting tones [10]). To minimize the performance degradation due to additive white Gaussian noise (AWGN), the signals in $\left\{p_{n}\right\}$ are chosen from those signal vectors with the largest energy level in the signal constellations [13]. It is assumed that the receiver has the prior knowledge of $\left\{p_{n}\right\}$, which therefore can be used to estimate the signal distortion introduced in the transmission path and subsequently makes the appropriate correction to the received data signal. At time $t=n T$ seconds, the symbol to be transmitted is used to form the impulse $q_{n} \delta(t-n T)$, which is fed to the premodulation filter with an impulse response $a(t)$. The $q_{n}$ is complex-valued and is either a data symbol or a pilot symbol, and $\delta(t)$ is the Dirac delta function. At the output of the premodulation filter, the signal becomes $\sum_{n} q_{n} a(t-n T)$. This signal is then used to linearly modulate a carrier signal to produce the transmit signal.

The transmission path in Fig. 1 is a land mobile satellite channel that introduces Rician fading to the transmitted signal [14]. The Rician-faded signal is composed of a direct component and a multipath component as shown in Fig. 4 [14]. The multipath component is assumed to be Rayleigh-faded and is generated by multiplying the direct component by a complex-valued parameter $h(t)$ to give $\Sigma_{n} q_{n} a(t-n T) h(t)$ as shown in Fig. 5. The two lowpass filters in Fig. 5 are two second-order Butterworth filters with the same normalized power-spectral-density of [15] 


$$
S(f)=\frac{1}{1+\left(f / f_{D}\right)^{4}}
$$

The quantity $f_{D}$ determines the maximum Doppler frequency of the multipath component and is given by [16]

$$
f_{D}=\frac{v}{\lambda}
$$

where $v$ is the radial velocity of the mobile and $\lambda$ is the wavelength of the signal carrier. Stationary AWGN is assumed to be added at the input of the receiver. In Fig. 5, the two amplifiers with a gain of $K$ are used to adjust the ratio of the direct-component power to the multipath-component power in the simulation tests. The ratio, CMR, is defined as

$$
\mathrm{CMR}=10\left[\log \left(\frac{C}{M}\right)\right] \mathrm{dB}
$$

where $C$ is the direct-component power and $M$ is the multipath-component power.

The baseband equivalent signal at the receiver is given by

$$
\begin{aligned}
& \sum_{n} q_{n} a(t-n T)+K \sum_{n} q_{n} a(t-n T) h(t)+v(t) \\
& =\sum_{n}\left[q_{n} a(t-n T) y(t)\right]+v(t)
\end{aligned}
$$

where $y(t)=1+K h(t)$ has been used. $K h(t)$ is the fading effects due to the multipath component introduced in the transmission path and $v(t)$ is the additive white Gaussian waveform with single-sided power spectrum of $N_{0}$.

The received signal is then filtered by a postdemodulation filter. The postdemodulation filter is taken to have the same impulse response $a(t)$ as the premodulation filter in the transmitter to give the corresponding baseband signal

$$
r(t)=\sum_{n} q_{n} a(t-n T) y(t) * a(t)+w(t)
$$


where * denotes the convolution process and $w(t)=v(t) * a(t)$ is the filtered noise waveform.

The Doppler shift of the received signal due to the motion of the mobile is assumed to be small compared to the symbol rate, so that the inter-symbol-interference (ISI) caused by the filtering process can be neglected. The baseband signal $r(t)$ is sampled in synchronism at the time instants $\{n T\}$. For convenience, it is assumed that $a(t) * a(t)=1$ at time $t=0$. Therefore, the sample signal at time $t=n T$ seconds is

$$
r_{n}=q_{n} y_{n}+w_{n}
$$

where $y_{n}=y(n T)$ and $w_{n}=w(n T)$. If $q_{n}$ is a pilot symbol and in the absence of noise, the signal $y_{n}$ can be obtained as

$$
y_{n}=\frac{r_{n}}{q_{n}}
$$

However, in the presence of noise, only an estimate of $y_{n}$ can be obtained. The estimate, $y_{n}^{\prime}$, is then used for fading compensation (estimation and correction) of the received data symbols in the associated frame. The corrected data symbols are fed to the detector and decoder to produce the binary data $\left\{u_{n}^{\prime}\right\}$ at the output. The proposed compensation technique is described in the following section. 


\section{Fade-Compensated Coherent Transmission Technique}

It is assumed in the following sections that frame synchronization of the received signal has been achieved. At the output of the postdemodulation filter, the sample signal at the $i$-th position of the $k$-th received frame is denoted by

$$
r_{k, i}=q_{k, i} y_{k, i}+w_{k, i}
$$

where $q_{k, i}$ is either a pilot symbol or a data symbol (Fig. 3). For $i=0$, the signal is

$$
r_{k, 0}=p_{k, 0} y_{k, 0}+w_{k, 0}
$$

where $p_{k, 0}$ is the pilot symbol of the $k$-th frame. For $i=1,2, \ldots, L-1$, the signal is

$$
r_{k, i}=d_{k, i} y_{k, i}+w_{k, i}
$$

where $d_{k, i}$ is a data symbol in the $k$-th frame. From Eq. (9), $y_{k, 0}$ can be written as

$$
y_{k, 0}=\frac{r_{k, 0}}{p_{k, 0}}-\frac{w_{k, 0}}{p_{k, 0}}
$$

Since the pilot symbol $p_{k, 0}$ is known at the receiver, at high signal-to-noise ratios, $y_{k, 0}$ can be estimated as

$$
y_{k, 0}^{\prime}=\frac{r_{k, 0}}{p_{k, 0}}
$$

In the previously developed algorithm where only the pilot symbols are used for fading estimation, $y_{k, 0}^{\prime}$ is obtained using Eq. (12) and treated as the estimates of the fading effects for the rest of the data symbols in the associated frame, i.e.,

$$
y_{k, i}^{\prime}=y_{k, 0}^{\prime} \quad \text { for } i=1,2, \ldots, L-1
$$

However, in the algorithm proposed in this paper, not only the pilot symbols, but also the data symbols are used for signal distortion estimation and hence for signal correction of 
the data symbols. The $y_{k, 0}^{\prime}$ obtained using Eq. (12) is subsequently treated as an estimate of $y_{k, 1}$ (the distortion effects in the first data symbol of the $k$-th frame), i.e.,

$$
y_{k, 1}^{\prime}=y_{k, 0}^{\prime}=\frac{r_{k, 0}}{p_{k, 0}}
$$

The signal is used to correct the fading effects in $r_{k, 1}$ to produce the corrected data signal

$$
r_{k, 1}^{\prime}=\frac{r_{k, 1}}{r_{k, 1}^{\prime}}
$$

The corrected data signal $r_{k, 1}^{\prime}$ is then fed to a threshold detector to give $d^{\prime}{ }_{k, 1}$, which is a possible signal vector on the constellation. The signal $d^{\prime}{ }_{k, 1}$ is subsequently decoded into binary data $\left\{u_{n}^{\prime}\right\}$. Since $d_{k, 1}^{\prime}$ is a possible signal vector on the constellation and $d_{k, 1}^{\prime}$ is closer to $y_{k, 2}$ in terms of time, a better estimate of $y_{k, 2}$ can be obtained as

$$
y_{k, 2}^{\prime \prime}=\frac{r_{k, 1}}{d_{k, 1}^{\prime}}
$$

Thus a better performance can be obtained if the signal $y_{k, 2}$ obtained from Eq.(16) is used, instead of $y_{k, 2}^{\prime}$ obtained using Eq. (13), to correct the second data symbol $r_{k, 2}$ in the same frame according to

$$
r_{k, 2}^{\prime}=\frac{r_{k, 2}}{y_{k, 2}^{\prime \prime}}
$$

This compensation process is carried out on each of the following data symbols until all the data symbols in the $k$-th frame have been corrected, i.e.,

$$
\begin{array}{ll}
y_{k, i}^{\prime \prime}=\frac{r_{k, i-1}}{d_{k, i-1}^{\prime}} & \text { for } i=2,3, \ldots, L-1 \\
r_{k, i}^{\prime}=\frac{r_{k, i}}{y_{k, i}^{\prime \prime}} & \text { for } i=2,3, \ldots, L-1
\end{array}
$$

Then the whole process repeats for every received signal frame. 


\section{Performance Degradation in a Gaussian Channel}

\subsection{Signal Energy Considerations}

Since the pilot symbols are known to the receiver, they carry no data information. However, the pilot symbols require a certain amount of power for transmission. Thus for a system with a fixed transmission power, a portion of the power has to be assigned for transmitting the pilot symbols. Therefore, the net average data-symbol energy is reduced. If the same transmit data-symbol energy as that without transmitting the pilot symbols is to be maintained, the average energy per data symbol has to be increased by

$$
\begin{aligned}
\Delta E_{s} & =10 \log \left[\left(\frac{L}{L-1}\right)\left(\frac{\left|P_{d}\right| \cdot \frac{L-1}{L}+\left|P_{p}\right| \cdot \frac{1}{L}}{\left|P_{d}\right|}\right)\right] \mathrm{dB} \\
& =10 \log \left[\left(\frac{\left|P_{p}\right|}{\left|P_{d}\right|}\right)\left(\frac{1}{L-1}\right)+1\right] \mathrm{dB}
\end{aligned}
$$

where $L$ is the frame length, $\left|P_{p}\right|$ and $\left|P_{d}\right|$ are the average energies required to transmit a pilot symbol and a data symbol, respectively.

For 16PSK signal, all the signal vectors have the same energy level, and Eq. (20) reduces to

$$
\Delta E_{s}=10 \log \left(\frac{L}{L-1}\right) \mathrm{dB}
$$

For 16QAM signal, since the pilot symbols are selected from those signal vectors with the largest signal levels in the constellation [13], $\left|P_{p}\right|:\left|P_{d}\right|=9: 5$ and Eq. (20) becomes

$$
\begin{aligned}
\Delta E_{s} & =10 \log \left[\frac{9}{5}\left(\frac{1}{L-1}\right)+1\right] \mathrm{dB} \\
& =10 \log \left[\frac{5 L+4}{5(L-1)}\right] \mathrm{dB}
\end{aligned}
$$


The theoretical BER performances of the coherent transmission of $16 \mathrm{PSK}$ and 16QAM signals in a Gaussian channel are given by [17]

$$
P_{b, 16 P S K} \approx \frac{1}{4} \operatorname{erfc}\left[\left(\frac{4 E_{b}}{N_{0}}\right)^{1 / 2} \sin \left(\frac{\pi}{16}\right)\right]
$$

and

$$
P_{b, 16 \mathrm{QAM}} \approx \frac{3}{8} \operatorname{erfc}\left[\left(\frac{6 E_{b}}{15 N_{0}}\right)^{1 / 2}\right] \times\left\{1-\frac{3}{8} \operatorname{erfc}\left[\left(\frac{6 E_{b}}{15 N_{0}}\right)^{1 / 2}\right]\right\}
$$

where $E_{b}$ is the average energy required to transmit a bit, and $N_{0}$ is the single-sided noise power-spectral-density of the AWGN. Taking into account of the loss of energy due to transmitting the pilot symbols, the BER performances for these two signals over a linear channel, with different values of frame length $L$, become

$$
P_{b, 16 P S K} \approx \frac{1}{4} \operatorname{erfc}\left[\left[4\left(\frac{E_{b}}{N_{0}}-\Delta E_{s}\right)\right]^{1 / 2} \sin \left(\frac{\pi}{16}\right)\right]
$$

and

$$
P_{b, 16 Q A M} \approx \frac{3}{8} \operatorname{erfc}\left[\left[\frac{6}{15}\left(\frac{E_{b}}{N_{0}}-\Delta E_{s}\right)\right]^{1 / 2}\right] \times\left\{1-\frac{3}{8} \operatorname{erfc}\left[\left[\frac{6}{15}\left(\frac{E_{b}}{N_{0}}-\Delta E_{s}\right)\right]^{1 / 2}\right]\right\}
$$

respectively, as shown in Fig. 6 . No compensation technique is used in these systems. It can be seen that, the longer the frame length $L$ is, the less is the performance degradation due to transmitting the pilot symbols.

\subsection{Bandwidth Considerations}

In addition to signal energy, bandwidth is also required to transmit the pilot symbols. If the same system throughput as that without transmitting the pilot symbols is to be maintained, the resultant symbol rate needs to be increased by a factor of $L /(L-1)$. Obviously, signal with a longer frame length requires less amount of extra bandwidth and extra energy for transmitting the pilot symbols. 


\subsection{Zero Time-Delay}

The perceptibility of voice communication degrades significantly for a message timedelay of more than $300 \mathrm{~ms}$. In geostationary satellite communications, the propagation delay for a single-hop system is already about $250 \mathrm{~ms}$. Although the future satellite-based PCS may use low-earth-orbit (LEO) satellites, any additional time delay (e.g. due to speech coding, forward-error-correction encoding, or fading compensation) may cause the total delay time to approach the limit of $300 \mathrm{~ms}$ and so should be minimized. In many other pilot symbol-aided algorithms where interpolation is used, the compensation processes cannot start until at least two pilot symbols have arrived. In this proposed algorithm, the storage delay introduced into the received message due to the compensation process is virtually zero because the compensation process for a frame can start immediately after the first symbol (the pilot symbol) of the frame is received. In addition, using the proposed technique, no storage of data symbol is required and the implementation is straight forward. 


\section{Simulation Results and Discussions}

A series of computer-simulation tests has been carried out to investigate the effectiveness of the proposed technique on the BER performances of an uncoded 16PSK and uncoded 16QAM signals used in the system of Fig. 1. The transmission path is assumed to be Rician-faded as shown in Fig. 4. In all tests, the baseband equivalent model as shown in Fig. 1 has been used. A CMR value of $7 \mathrm{~dB}$, which is specified in the INMARSAT systems specifications, has been assumed throughout the tests [14]. The signal-to-noise ratio (SNR) is taken as

$$
\mathrm{SNR}=10\left[\log \left(\frac{E_{b}}{N_{0}}\right)\right] \mathrm{dB}
$$

where $E_{b}$ is the average energy required to transmit a bit (after taking into account of the pilot symbols) and $N_{0}$ is the single-sided power spectral density of the AWGN. The resultant transfer function of the premodulation filter and the postdemodulation filter in cascade has a sinusoidal roll-off of $100 \%$. For convenience, the systems are assumed to be operating at a rate of $32 \mathrm{~kb} / \mathrm{s}$ or $8 \mathrm{kbauds}$ (i.e., a symbol period of $0.125 \mathrm{~ms}$ ) with the signal carrier frequency of $1.8 \mathrm{GHz}$.

With the frame lengths of $L=8,16,32$ and 64, and when the mobile is travelling at the radial velocities of $v=24 \mathrm{~km} / \mathrm{hr}, 48 \mathrm{~km} / \mathrm{hr}$, and $96 \mathrm{~km} / \mathrm{hr}$ resulting in the worst normalized Doppler spreads of $f_{D} T=0.005,0.01$ and 0.02 of the symbol rate, the simulation results of the 16PSK and 16QAM signals are shown in Figs. 7, 8 and 9, respectively. It can be seen that the 16QAM signal outperforms the 16PSK signal in all the conditions tested. At lower velocities, both signals have better BER performances. This is expected because the signals fade more slowly at high velocities than at lower velocities and the fading effects between the pilot symbol and the data symbols in the associated frame are therefore more correlated. As a result, the estimates of the fading effects and hence the correction of the signals are more accurate, leading to a better performance. 
Since the practical values of BERs for digital voice communications are around $10^{-3}$, it is interesting to see how much the technique can reduce the required SNRs of the 16PSK and 16QAM signals for achieving this BER. Using the results of Figs. 7, 8 and 9, the SNRs required for the signals to achieve a BER of $10^{-3}$ are shown in Table 1. It can be seen that, if only the pilot symbols are used for fading correction, the 16PSK signal cannot achieve the BER of $10^{-3}$ in all the conditions tested; while the 16QAM can achieve this BER only in one test, i.e., when $v=24 \mathrm{~km} / \mathrm{hr}$ and $L=8$. However, if the data symbols as well as the symbols are used, i.e., the propsoed technique, then the 16QAM and 16PSK signals can achieve the BER of $10^{-3}$ in most of the tests.

To further access the effectiveness of the proposed technique, the SNR values at which the 16PSK and 16QAM signals using the technique start to gain advantages in BER performances are shown in Table 2. It can be seen that, by using the technique and in all the conditions tested, both the 16PSK and 16QAM signals start to gain BER performance advantages in the SNR range from $13 \mathrm{~dB}$ to $25 \mathrm{~dB}$. For a given frame length $L$, the signals start to gain BER performance advantages at lower SNRs with higher radial velocities, for the same reason described previously. At a given radial velocity, the signals start to gain advantages at lower SNRs with longer frame lengths. The lowest SNRs for the 16PSK and 16QAM to start gaining BER performance advantages are 13.5 and $13 \mathrm{~dB}$, respectively, which occur when the frame length $L=64$ and the radial velocity $v=96 \mathrm{~km} / \mathrm{hr}$. If the frame length is decreased to $L=8$, the respective SNR values are reduced to 15.5 and $17 \mathrm{~dB}$. However, if the frame length is maintained at $L=64$ but the radial velocity is decreased to 24 $\mathrm{km} / \mathrm{hr}$ instead, the SNR values for both signals are reduced to $15 \mathrm{~dB}$.

Finally, it may be interesting to look at the improvements in BER performances at very high SNRs. Figures. 7, 8 and 9 show that, at the SNR of $40 \mathrm{~dB}$ where the error-rate floors of the signals occur, substantial improvements in the BER performances can be obtained by using both the pilot symbols and data symbols in the compensation process, instead of using only the pilot symbols. The longer the frame length is, the better is the improvement of the performance. However, the shorter the frame length is, the better is the 
BER performance. For example, at a radial velocity of $v=24 \mathrm{~km} / \mathrm{hr}$ (i.e., $f_{D} T=0.005$ ), Fig. 7 shows that if both the pilot symbols and data symbols are used, the BERs of the 16PSK and 16QAM signals can be reduced by factors of about 233 (from $9.8 \times 10^{-2}$ to $4.2 \times 10^{-4}$ ) and 281 (from $5.9 \times 10^{-2}$ to $2.1 \times 10^{-4}$ ), respectively, at a $\mathrm{SNR}=40 \mathrm{~dB}$ and $L=64$. A better performance can be achieved by using a shorter frame length. With $L=8$, the BERs of the 16PSK and 16QAM signals are reduced from $1.1 \times 10^{-3}$ to $8.4 \times 10^{-5}$ and from $3.0 \times 10^{-4}$ to $4.1 \times 10^{-5}$, respectively. Table 3 lists the factors of improvements on the BER performances of the signals using the proposed technique. It is evident that the proposed technique is more effective when the mobile is travelling at slow radial velocities (i.e. in the small Doppler spread environments), in the sense that better improvements can be obtained, relative to those of using only the pilot symbols for compensation. At higher velocities or in the large Doppler spread environments, shorter frame lengths should be used for achieving better performances. 


\section{Conclusions}

A novel fade-compensation technique using both the received pilot symbols and data symbols, instead of only the pilot symbols, for the coherent transmission of spectrallyefficient signals in the land mobile satellite channels has been proposed. The technique is particularly suitable for voice transmission over the satellite channels because the compensation process for a frame can start immediately after the first symbol (the pilot symbol) is received. The effects of the technique on the BER performances of an uncoded 16PSK and uncoded 16QAM signals have been studied using computer simulations. It has been shown that the 16QAM signal outperforms the 16PSK signal in all the conditions tested.

If only the pilot symbols are used for fading correction, the 16PSK signal cannot achieve the practical BER of $10^{-3}$ for voice communcations. However, by using the proposed technique, the 16PSK and 16QAM signals can achieve the BER in most of the conditions tested. The proposed technique has substantial improvements in the BER performance of the 16PSK and 16QAM signals over the conventional technique which employs only the pilot symbols for fading estimation. In all the test carried out, these improvements occur in the SNR range from $13 \mathrm{~dB}$ to $25 \mathrm{~dB}$.

The proposed technique also reduces the error-rate floors of the 16PSK and 16QAM signals substantially. The reductions are more significant with the mobile traveling at slow radial velocities (i.e., with smaller Doppler spreads) and longer frame lengths. 


\section{References}

[1] E. Del. Re, “A Satellite Mobile System Integrated with the Terrestrial Cellular Network," in Proceedings of the IEEE International Conference on Communications, U.S.A., June 1989, pp. 223-227.

[2] E. E. Reinhart, “Mobile Communications,” IEEE Spectrum, vol. 29, no. 2, pp. 27-29, February, 1992.

[3] H. K. Lau, "Interworking of Satellite and Terrestrial Mobile Communication Systems," M.Phil. Thesis, Department of Electronic Engineering, Hong Kong Polytechnic University, Hong Kong, 1992.

[4] D. C. Cox, "Wireless Personal Communications: What is it?," IEEE Personal Communications, vol. 2, no. 2., April 1995.

[5] K. M. S. Murthy, V. K. Bhargava, and A. Boettcher, "Personal SATCOM Systems and Services," Tutorial Record in Proceedings of the IEEE International Conference on Universal Personal Communications, San Diego, U.S.A., September 1994.

[6] S. W. Cheung and A. H. Aghvami, "Performance Study of 16-ary DEQAM Modem for Future Satellite Communication Systems," International Journal of Satellite Communications, vol. 7, no. 5, December 1989, pp. 413-423.

[7] W. T. Webb, "QAM: The Modulation Scheme for Future Mobile Radio Communications ?,” Electronics and Communication Engineering Journal, vol. 4, no. 4., 1992, pp. 167-176.

[8] C. L. Liu and K. Feher, "Pilot-Symbol Aided Coherent M-ary PSK in FrequencySelective Fast Rayleigh Fading Channels,” IEEE Transactions on Communications, vol. 42, no. 1, January 1994, pp. 54-62.

[9] W. J. Weber, "Performance of Phase-Lock Loops in the Presence of Fading Communication Channels," IEEE Transactions on Communications, vol. 24, no. 5, May 1976, pp. 487-499.

[10] J. K. Cavers, “An Analysis of Pilot Symbol Assisted Modulation for Rayleigh Fading Channels,” IEEE Transactions on Vehicular Technology, vol. 40, no. 4, pp. 686-693, November 1991.

[11] S. Sampei and T. Sunaga, "Rayleigh Fading Compensation for QAM in Land Mobile Radio Communications,” IEEE Transactions on Vehicular Technology, vol. 42, no. 2, pp. 137-147, May 1993.

[12] G. T. Irvine and P. J. McLane, "Symbol-Aided Plus Decision-Directed Reception for PSK/TCM Modulation on Shadowed Mobile Satellite Fading Channels," IEEE Journal on Selected Areas in Communications, vol. 10, no. 8, pp. 1289-1299, October 1992.

[13] H. K. Lau and S. W. Cheung, "A Pilot Symbol-Aided Technique Used for Digital Signals in Multipath Environments," in Proceedings of the IEEE International Conference on Communications, New Orleans, U.S.A., May 1994, pp. 1126-1130.

[14] Inmarsat, INMARSAT Standard-C System Definition Manual, Module 4, 1989. 
[15] L. J. Mason, "Error Probability Evaluation for Systems Employing Differential Detection in a Rician Fast Fading Environment and Gaussian Noise,” IEEE Transactions on Communications, vol. 35, no. 1, January 1987, pp. 39-46.

[16] H. Salwch, "Differential phase-shift keying performance under time-selecting multipath fading", IEEE Transactions on Communications, vol. 23, March 1975, pp. 383-385.

[17] M. C. Jeruchim, P. Balaban, and K. S. Shanmugan, Simulation of Communication Systems, Plenum Press, New York, pp. 706-708.

Table 1. SNRs required for a) 16PSK and b) 16QAM to achieve a BER of $10^{-3}$

Table 1 (a)

\begin{tabular}{|c|c|c|c|c|c|c|}
\hline$v=$ & \multicolumn{2}{|c|}{$24 \mathrm{~km} / \mathrm{hr}$} & \multicolumn{2}{c|}{$48 \mathrm{~km} / \mathrm{hr}$} & \multicolumn{2}{c|}{$96 \mathrm{~km} / \mathrm{hr}$} \\
\hline Frame Length & Pilot & Pilot+Data & Pilot & Pilot+Data & Pilot & Pilot+Data \\
\hline$L=8$ & $\mathrm{X}$ & $25 \mathrm{~dB}$ & $\mathrm{X}$ & $26.5 \mathrm{~dB}$ & $\mathrm{X}$ & $32.5 \mathrm{~dB}$ \\
\hline$L=16$ & $\mathrm{X}$ & $26.5 \mathrm{~dB}$ & $\mathrm{X}$ & $29 \mathrm{~dB}$ & $\mathrm{X}$ & $\mathrm{X}$ \\
\hline$L=32$ & $\mathrm{X}$ & $28.5 \mathrm{~dB}$ & $\mathrm{X}$ & $33.5 \mathrm{~dB}$ & $\mathrm{X}$ & $\mathrm{X}$ \\
\hline$L=64$ & $\mathrm{X}$ & $31 \mathrm{~dB}$ & $\mathrm{X}$ & $\mathrm{X}$ & $\mathrm{X}$ & $\mathrm{X}$ \\
\hline
\end{tabular}

Table 1 (b)

\begin{tabular}{|c|c|c|c|c|c|c|}
\hline$v=$ & \multicolumn{2}{|c|}{$24 \mathrm{~km} / \mathrm{hr}$} & \multicolumn{2}{c|}{$48 \mathrm{~km} / \mathrm{hr}$} & \multicolumn{2}{c|}{$96 \mathrm{~km} / \mathrm{hr}$} \\
\hline Frame Length & Pilot & Pilot+Data & Pilot & Pilot+Data & Pilot & Pilot+Data \\
\hline$L=8$ & $20.5 \mathrm{~dB}$ & $23 \mathrm{~dB}$ & $\mathrm{X}$ & $24 \mathrm{~dB}$ & $\mathrm{X}$ & $25 \mathrm{~dB}$ \\
\hline$L=16$ & $\mathrm{X}$ & $24 \mathrm{~dB}$ & $\mathrm{X}$ & $25 \mathrm{~dB}$ & $\mathrm{X}$ & $28 \mathrm{~dB}$ \\
\hline$L=32$ & $\mathrm{X}$ & $25 \mathrm{~dB}$ & $\mathrm{X}$ & $27.5 \mathrm{~dB}$ & $\mathrm{X}$ & $33.5 \mathrm{~dB}$ \\
\hline$L=64$ & $\mathrm{X}$ & $27 \mathrm{~dB}$ & $\mathrm{X}$ & $30 \mathrm{~dB}$ & $\mathrm{X}$ & $\mathrm{X}$ \\
\hline
\end{tabular}


Table 2. SNRs at which the technique starts gaining advantages for 16PSK and 16QAM

\begin{tabular}{|c|c|c|c|c|c|c|}
\hline & \multicolumn{3}{|c|}{$16 \mathrm{PSK}$} & \multicolumn{3}{c|}{$16 \mathrm{QAM}$} \\
\hline Frame Length & $24 \mathrm{~km} / \mathrm{hr}$ & $48 \mathrm{~km} / \mathrm{hr}$ & $96 \mathrm{~km} / \mathrm{hr}$ & $24 \mathrm{~km} / \mathrm{hr}$ & $48 \mathrm{~km} / \mathrm{hr}$ & $96 \mathrm{~km} / \mathrm{hr}$ \\
\hline$L=8$ & $21.5 \mathrm{~dB}$ & $17.5 \mathrm{~dB}$ & $15.5 \mathrm{~dB}$ & $25 \mathrm{~dB}$ & $20.5 \mathrm{~dB}$ & $17 \mathrm{~dB}$ \\
\hline$L=16$ & $17.5 \mathrm{~dB}$ & $15.5 \mathrm{~dB}$ & $14.5 \mathrm{~dB}$ & $20.5 \mathrm{~dB}$ & $16.5 \mathrm{~dB}$ & $14.5 \mathrm{~dB}$ \\
\hline$L=32$ & $16.5 \mathrm{~dB}$ & $14.5 \mathrm{~dB}$ & $13 \mathrm{~dB}$ & $17 \mathrm{~dB}$ & $14 \mathrm{~dB}$ & $13 \mathrm{~dB}$ \\
\hline$L=64$ & $15 \mathrm{~dB}$ & $14.5 \mathrm{~dB}$ & $13.5 \mathrm{~dB}$ & $15 \mathrm{~dB}$ & $13.5 \mathrm{~dB}$ & $13 \mathrm{~dB}$ \\
\hline
\end{tabular}

Table 3. Factors of improvments on BER Performance using the proposed technique

\begin{tabular}{|c|c|c|c|c|c|c|}
\hline$v=$ & \multicolumn{2}{|c|}{$24 \mathrm{~km} / \mathrm{hr}$} & \multicolumn{2}{c|}{$48 \mathrm{~km} / \mathrm{hr}$} & \multicolumn{2}{c|}{$96 \mathrm{~km} / \mathrm{hr}$} \\
\hline Frame Length & PSK & QAM & PSK & QAM & PSK & QAM \\
\hline$L=8$ & 13 & 7 & 24 & 12 & 25 & 23 \\
\hline$L=16$ & 79 & 40 & 74 & 60 & 48 & 74 \\
\hline$L=32$ & 182 & 150 & 103 & 141 & 52 & 92 \\
\hline$L=64$ & 233 & 281 & 93 & 178 & 38 & 86 \\
\hline
\end{tabular}




\section{List of Figures}

Fig. 1 System model of data-transmission system

Fig. 2 16PSK and 16QAM signal constellations

Fig. 3 Frame structure of transmitted symbols

Fig. 4 Model of transmission path

Fig. 5 Model to generate the multipath component in Figure 4

Fig. 6 Performances of 16PSK and 16QAM in a Gaussian channel with different values of $L$

Fig. 7 Performances of a) 16PSK and b) 16QAM in Rician channels with CMR $=7 \mathrm{~dB}$, $v=24 \mathrm{~km} / \mathrm{hr}\left(f_{D} T=0.005\right)$ and different values of $L$ used for fade-compensation

Fig. 8 Performances of a) 16PSK and b) 16QAM in Rician channels with CMR $=7 \mathrm{~dB}$, $v=48 \mathrm{~km} / \mathrm{hr}\left(f_{D} T=0.01\right)$ and different values of $L$ used for fade-compensation

Fig. 9 Performances of a) 16PSK and b) 16QAM in Rician channels with CMR $=7 \mathrm{~dB}$, $v=96 \mathrm{~km} / \mathrm{hr}\left(f_{D} T=0.02\right)$ and different values of $L$ used for fade-compensation 


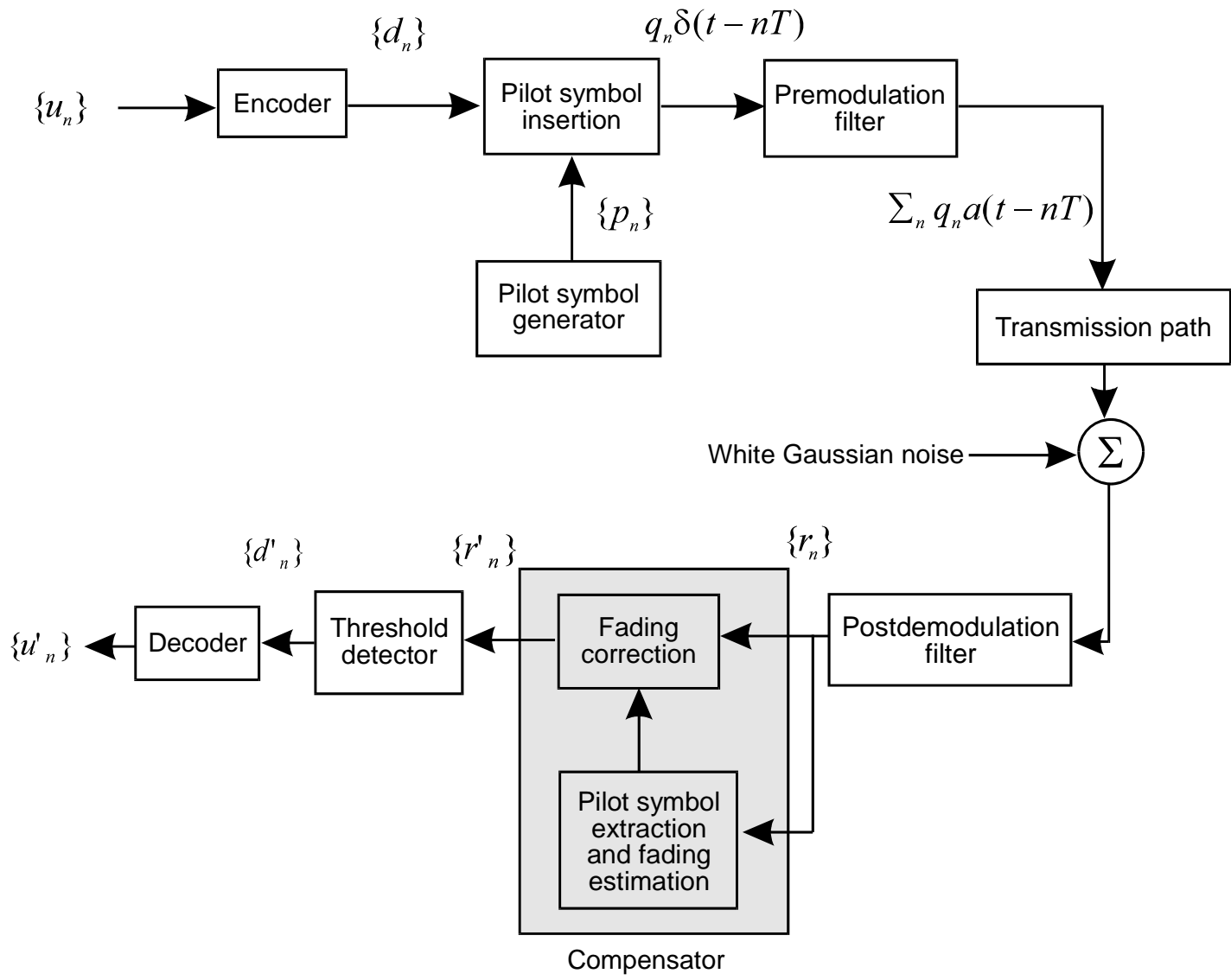

Fig. 1 System model of data-transmission system 


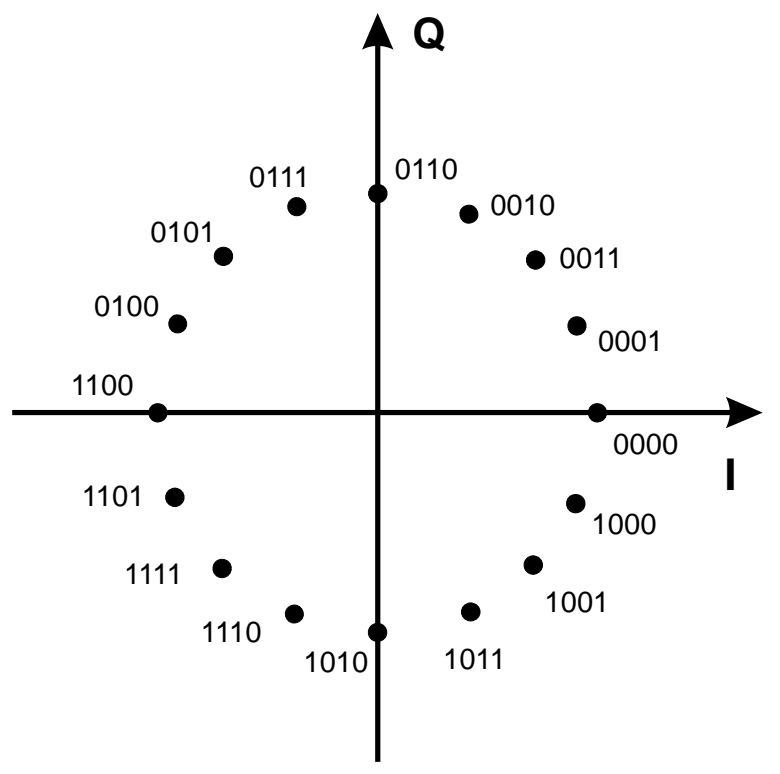

16PSK

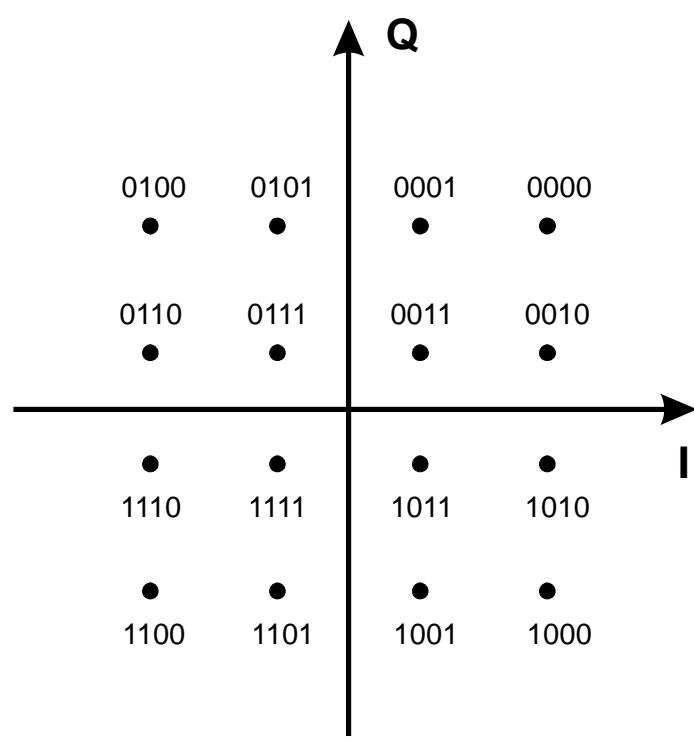

16QAM

Fig. 2 16PSK and 16QAM signal constellations

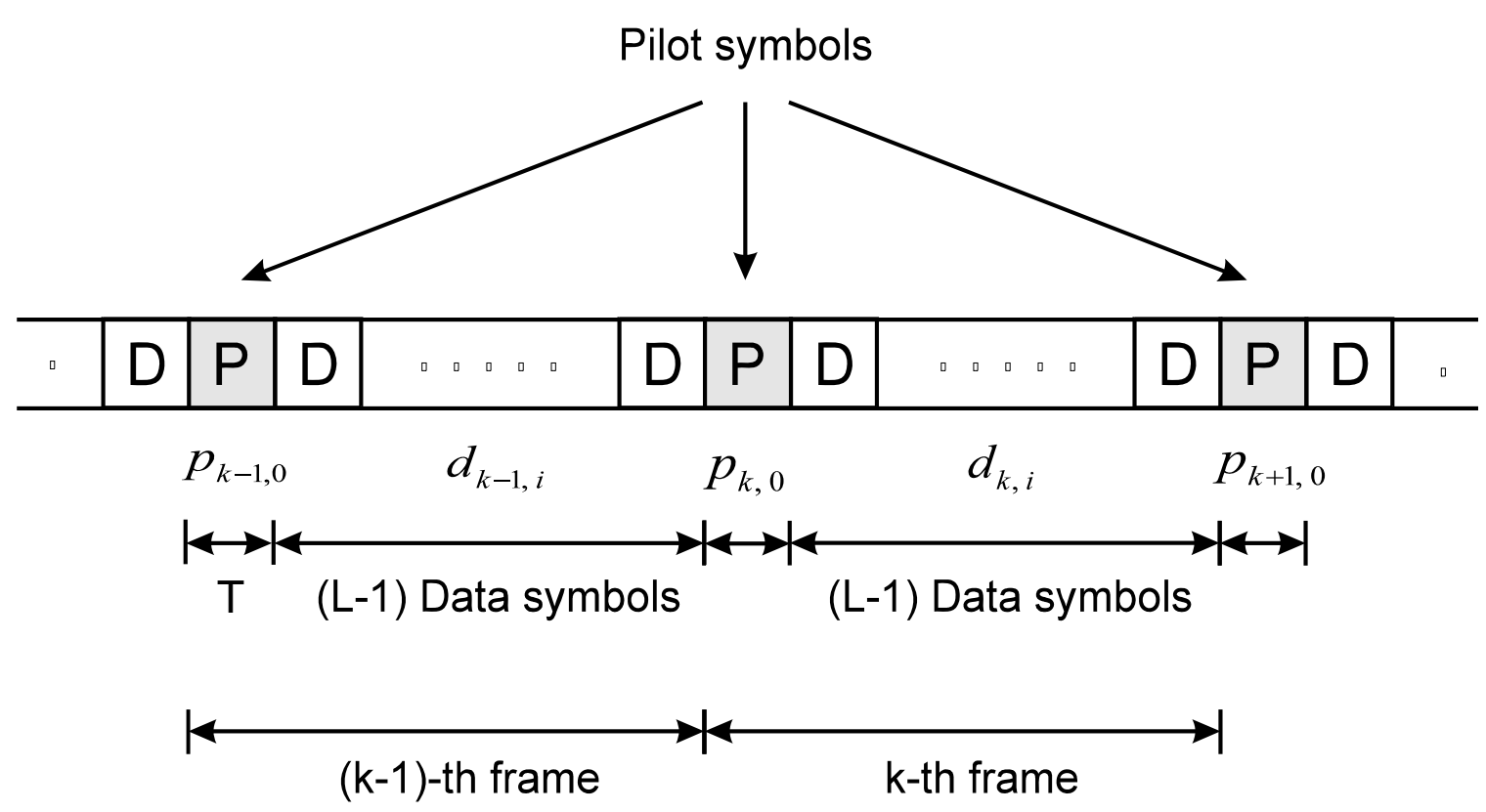

Fig. 3 Frame structure of transmitted symbols 


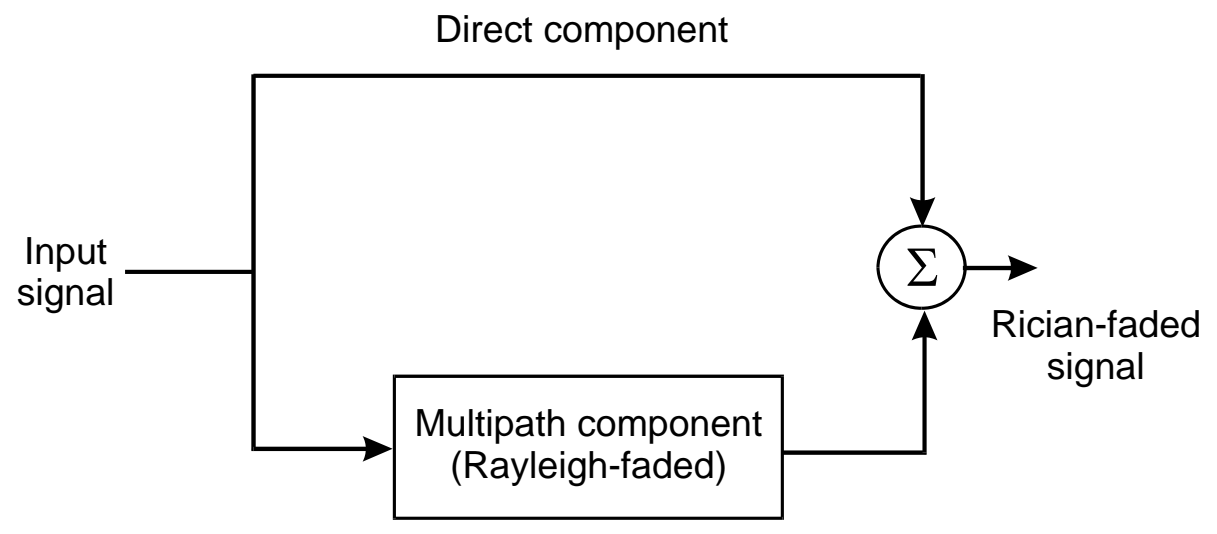

Fig. 4 Model of transmission path

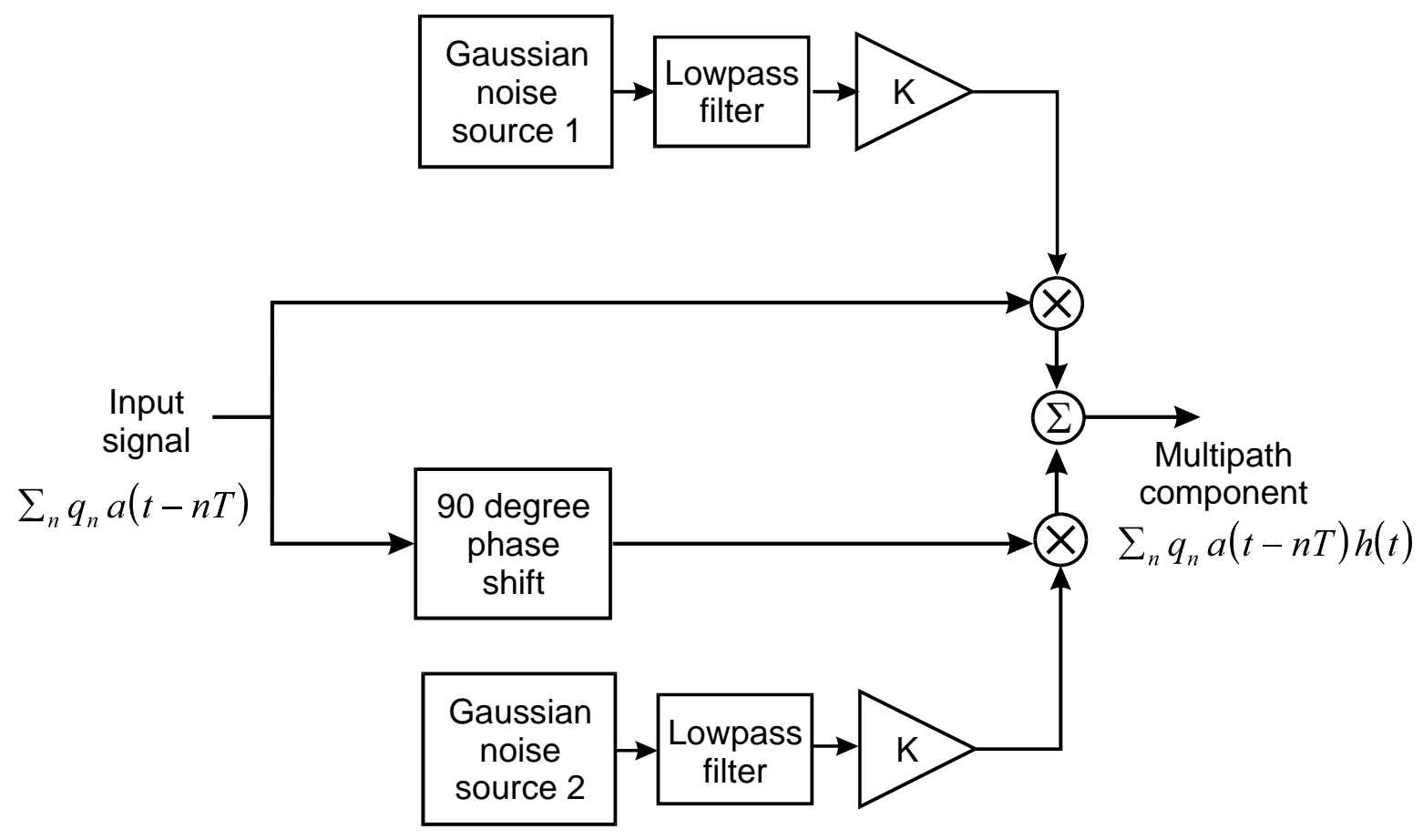

Fig. 5 Model to generate the multipath component in Figure 4 


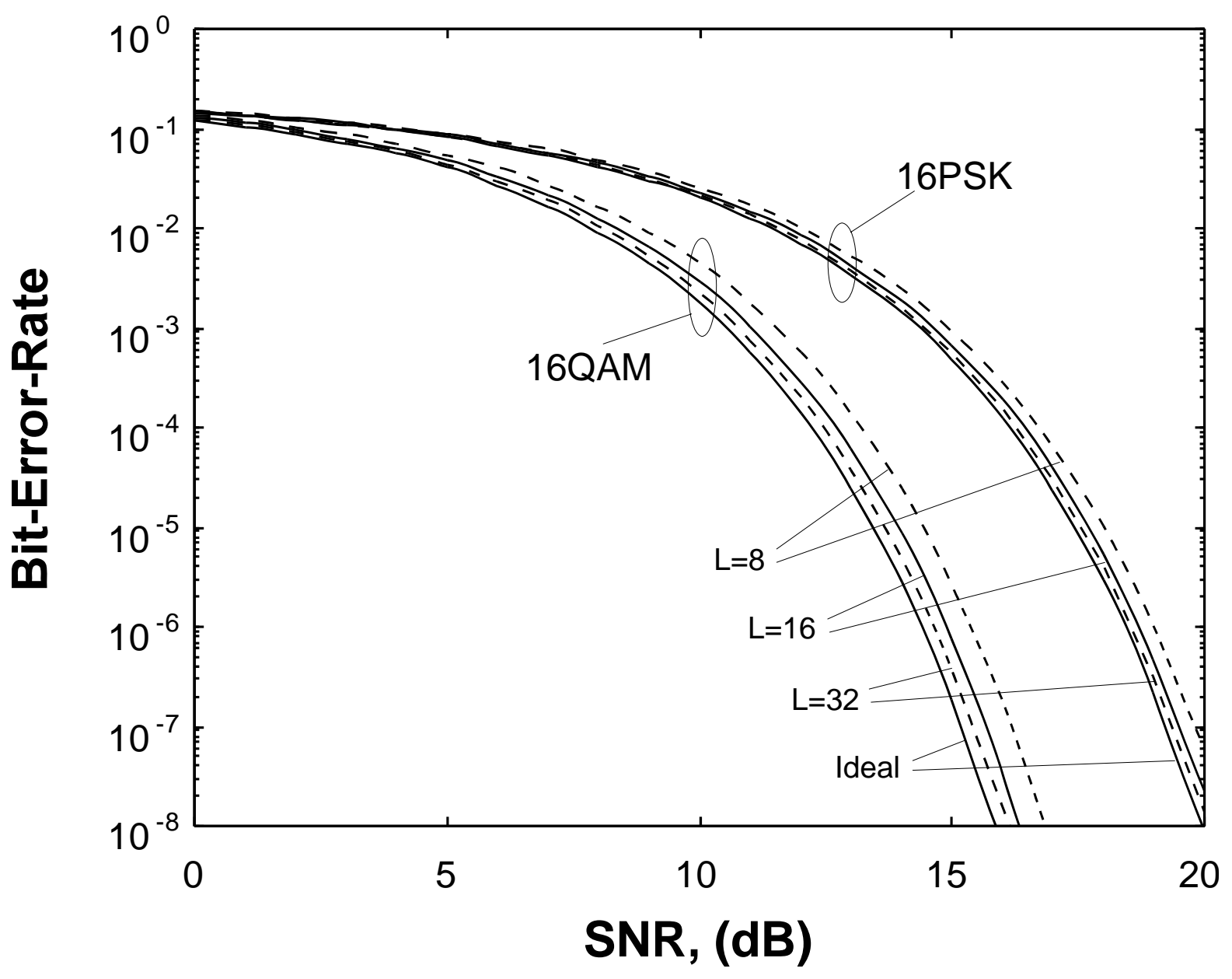

Fig. 6 Performances of 16PSK and 16QAM in a Gaussian channel with different values of $L$ 


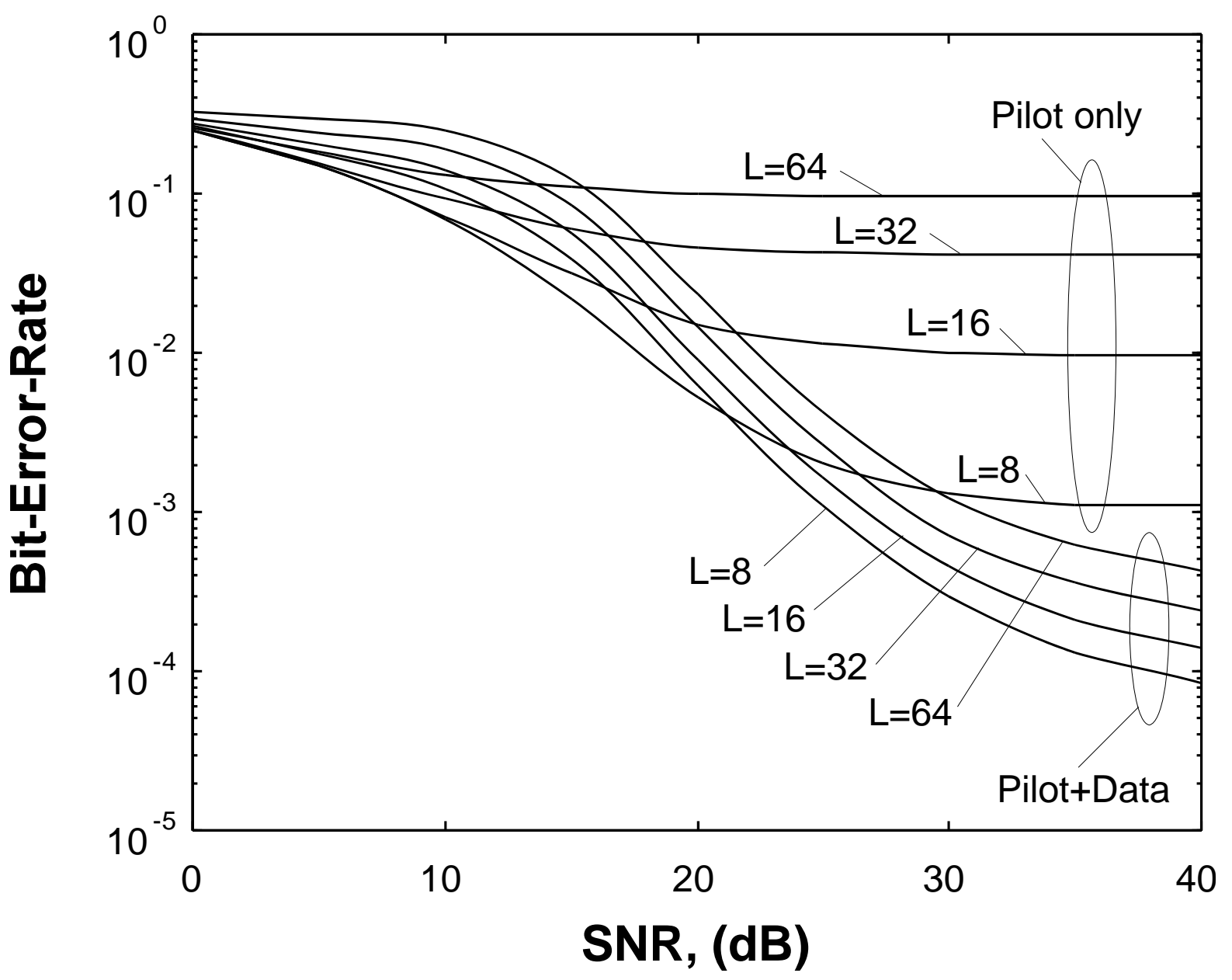

Figure $7 \mathrm{a}$

Fig. 7 Performances of a) 16PSK and b)16QAM in Rician channel with CMR $=7 \mathrm{~dB}, v$ $24 \mathrm{~km} / \mathrm{hr}\left(f_{D} T=0.005\right)$ and different values of $L$ used for fade-compensation 


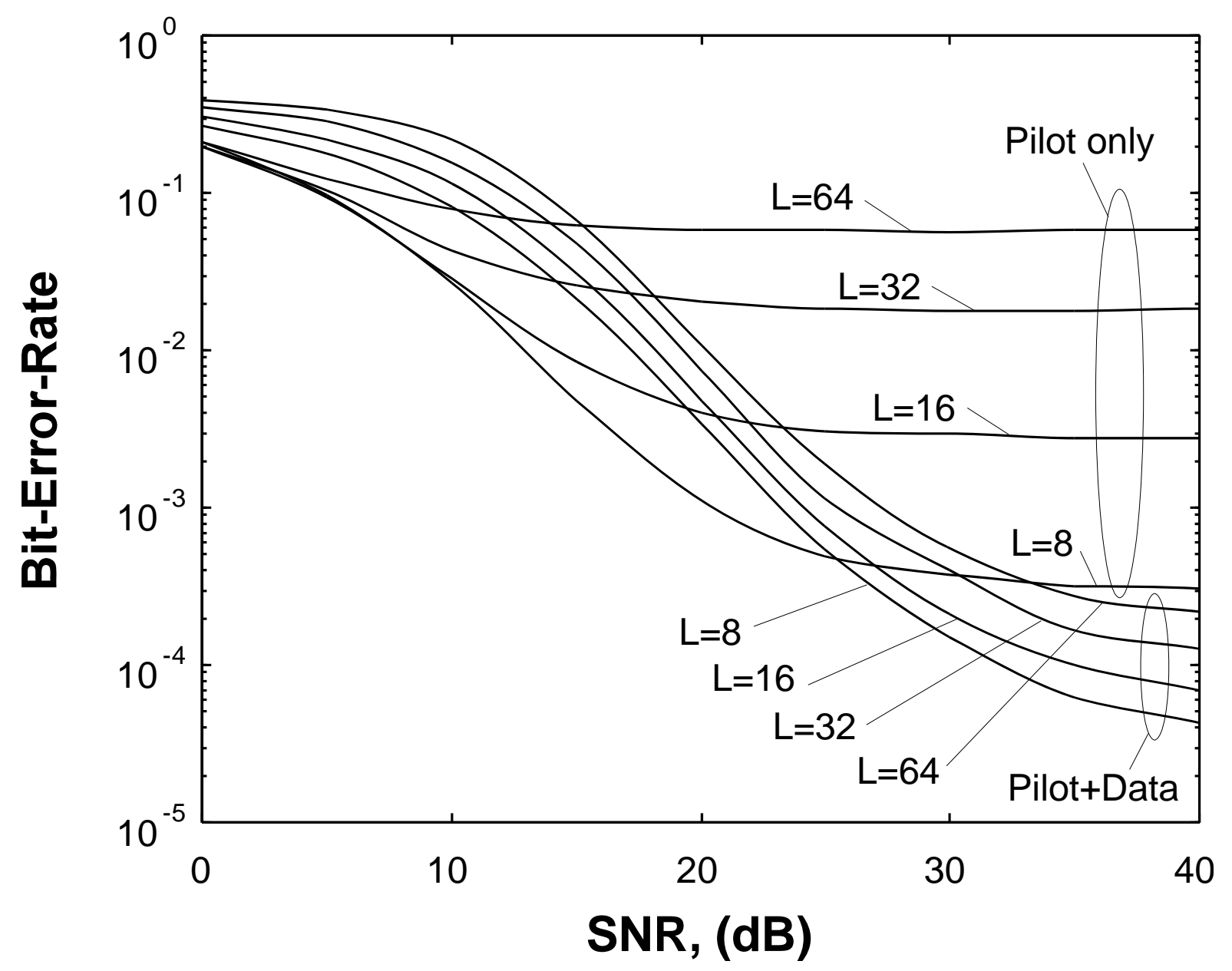

Fig. 7b 


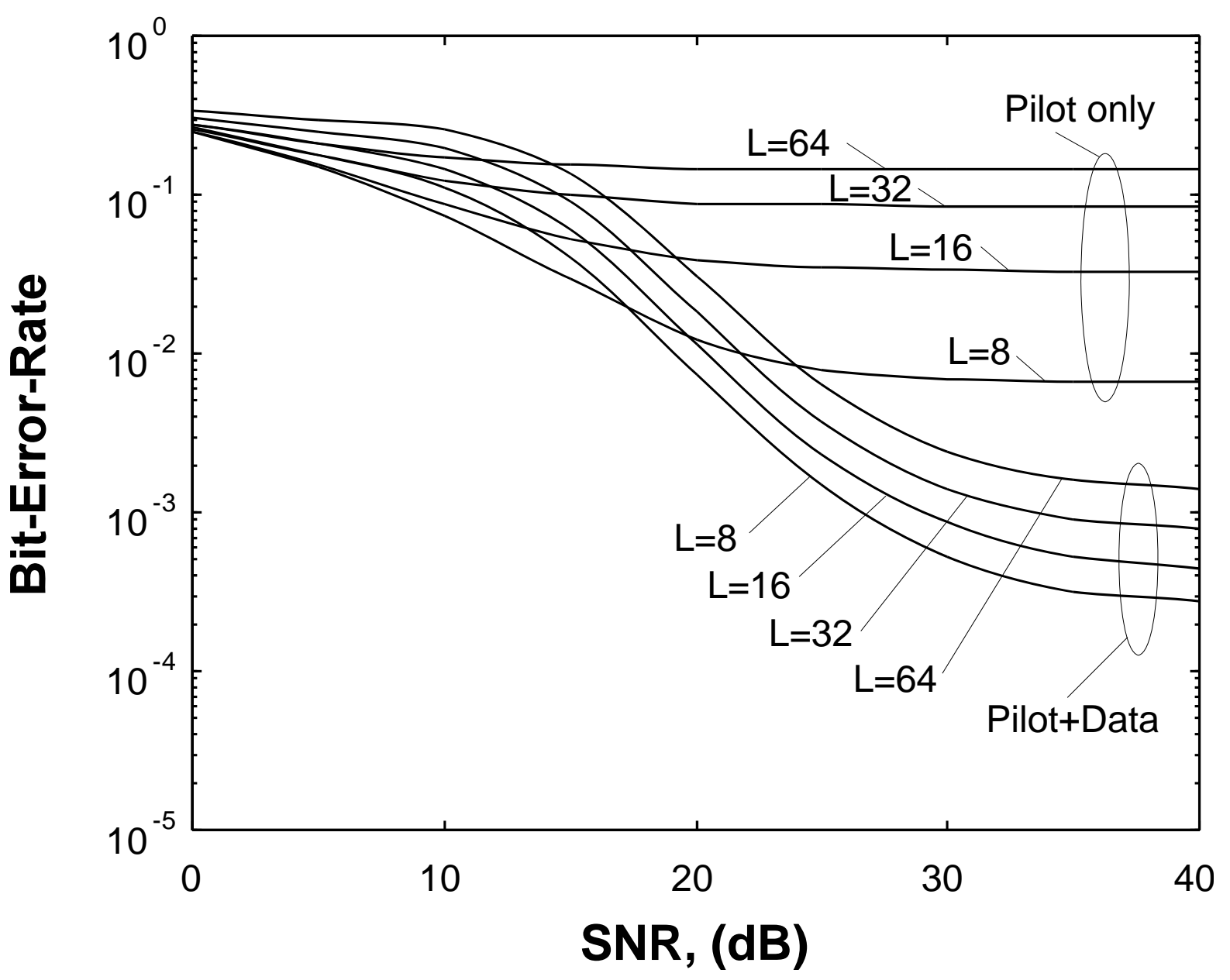

Fig. 8a

Fig. 8 Performances of a) 16PSK and b)16QAM in Rician channel with CMR $=7 \mathrm{~dB}, v$ $=48 \mathrm{~km} / \mathrm{hr}\left(f_{D} T=0.01\right)$ and different values of $L$ used for fade-compensation 


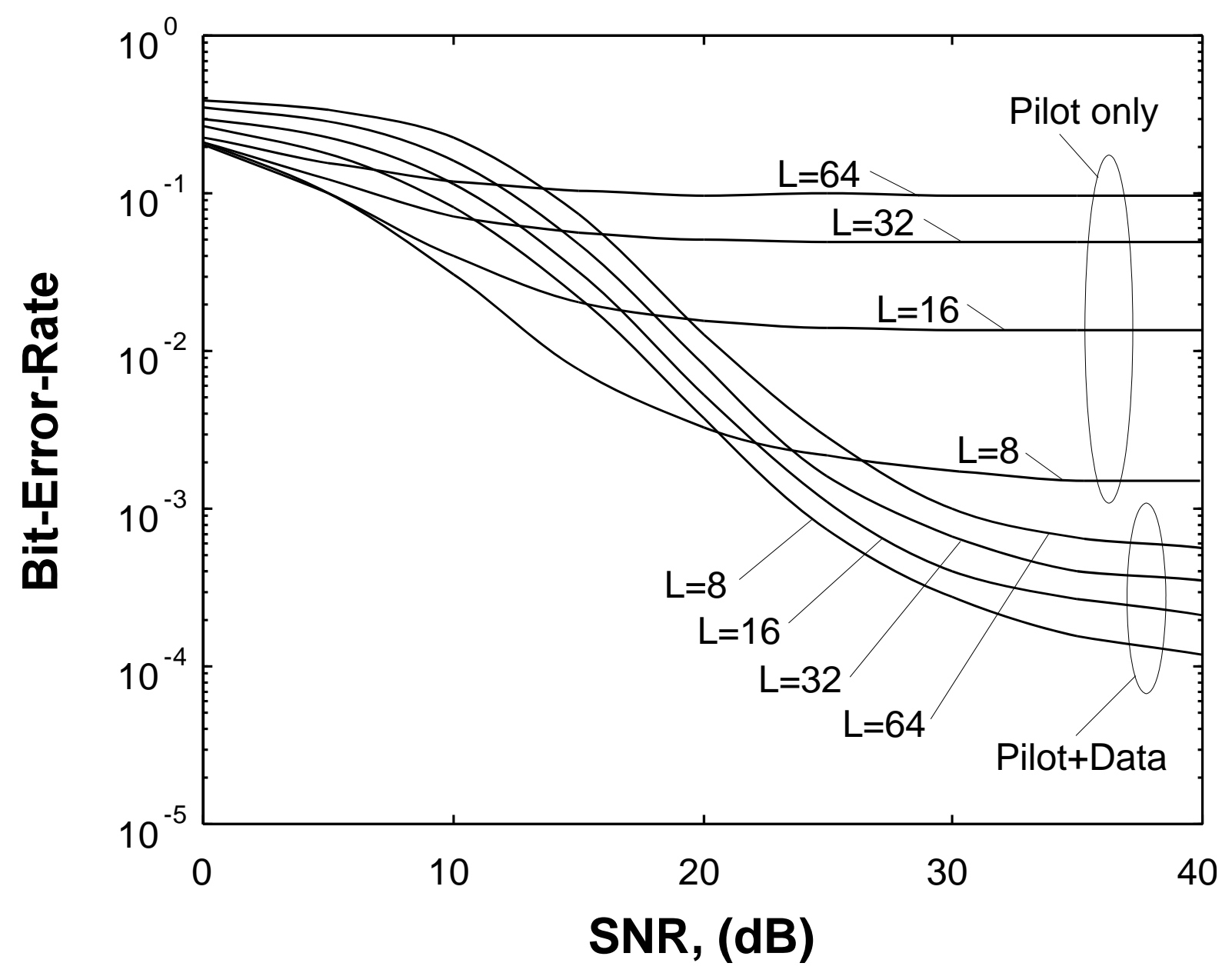

Fig. 8b 


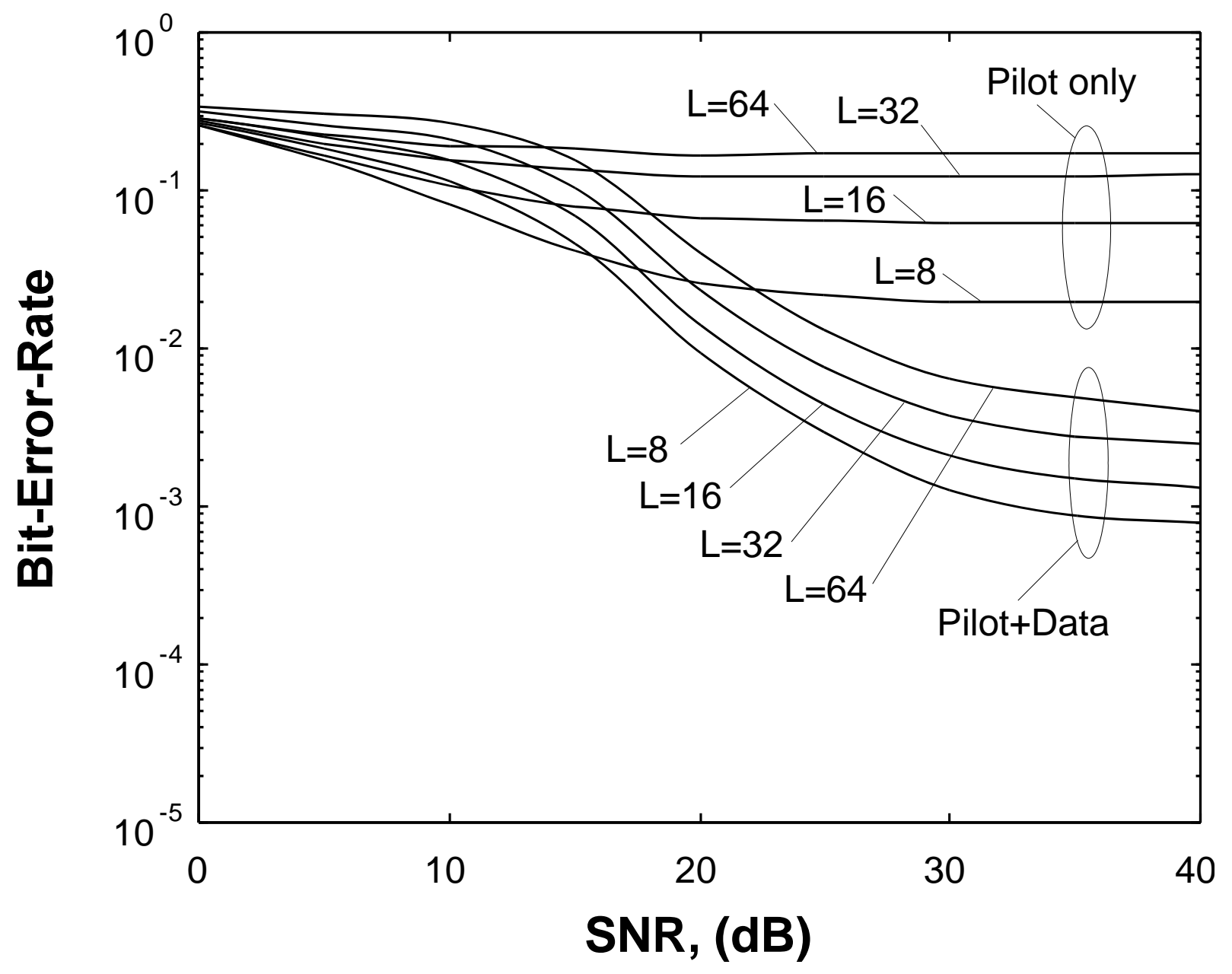

Fig. 9a

Fig. 9 Performances of a) 16PSK and b)16QAM in Rician channel with CMR $=7 \mathrm{~dB}, v$ $=96 \mathrm{~km} / \mathrm{hr}\left(f_{D} T=0.02\right)$ and different values of $L$ used for fade-compensation 


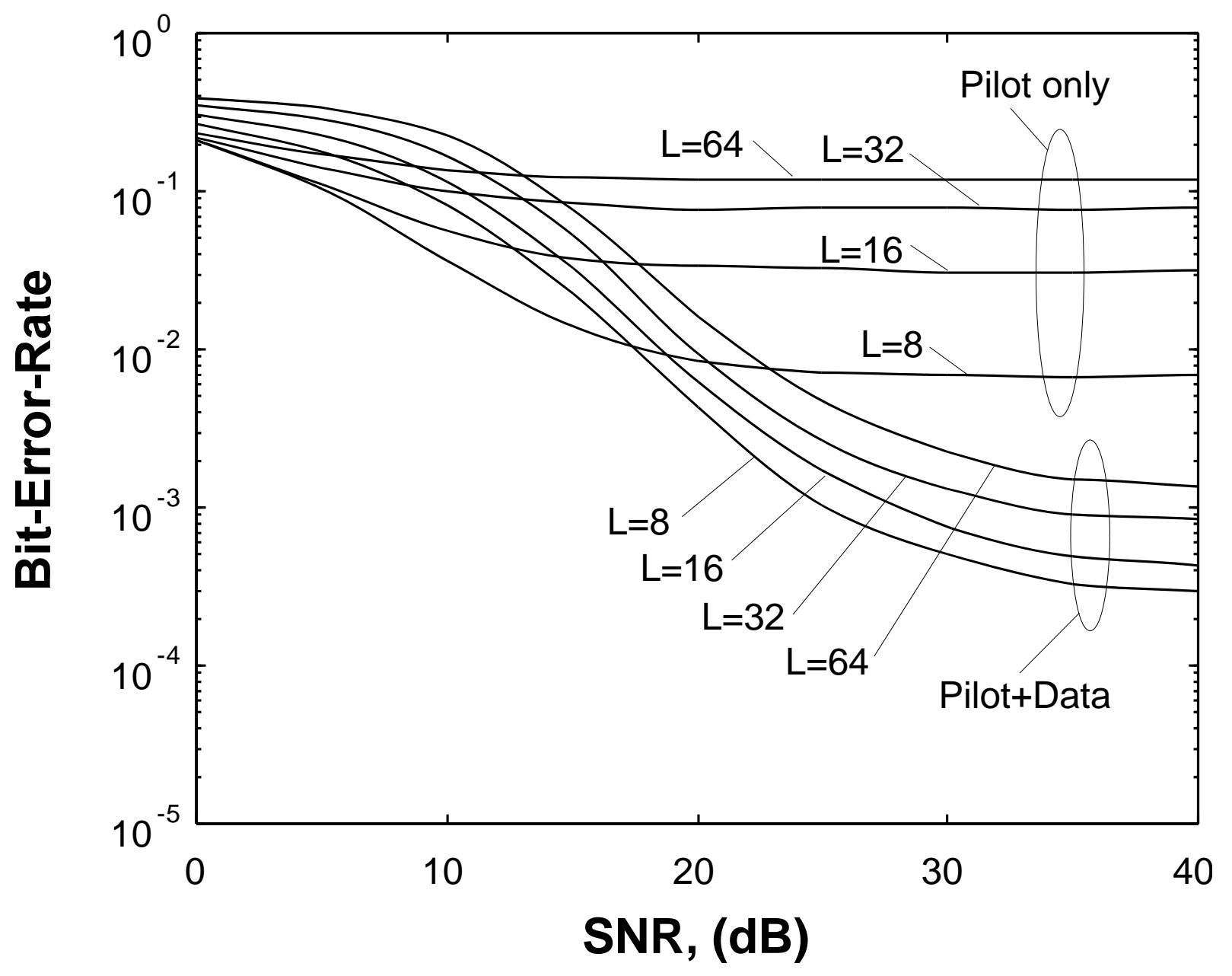

Fig. 9b 